Original Research Paper

\title{
Response Surface Optimized Ultrasonic Assisted Extraction of Total Flavonoids from Walnut Leaves and In Vitro Antibacterial Activities
}

\author{
${ }^{1}$ Jingjing Fu, ${ }^{1}$ Haifang Xiao, ${ }^{1}$ Shaoxuan Yu, ${ }^{1}$ Han Wu, ${ }^{2}$ Aydin Berenjian and ${ }^{1}$ Yuanda Song \\ ${ }^{1}$ Colin Ratledge Center for Microbial Lipids, School of Agriculture Engineering and Food Science, \\ Shandong University of Technology, Zibo, Shandong, China \\ ${ }^{2}$ School of Engineering, Faculty of Science and Engineering, the University of Waikato, Hamilton, New Zealand
}

\author{
Article history \\ Received: 22-09-2017 \\ Revised: 09-10-2017 \\ Accepted: 18-10-2017 \\ Corresponding Author: \\ Yuanda Song \\ Colin Ratledge Center for \\ Microbial Lipids, School of \\ Agriculture Engineering and \\ Food Science, Shandong \\ University of Technology, \\ Zibo, Shandong, China \\ Email: ysong@sdut.edu.cn
}

\begin{abstract}
In this paper, the optimum extraction conditions of total flavonoids extracted from walnut leaves subjected to Ultrasonic Assisted Extraction (UAE) were optimized by Response Surface Methodology (RSM). The mathematical model showed the high coefficient of measurement $\left(\mathrm{R}^{2}=0.9938\right)$ which indicated that this model could be used to guide the response surface methodology. The optimum extraction parameters for extracting flavonoids from walnut leaves determined in this study were extraction temperature $47.73^{\circ} \mathrm{C}$, extraction time $30.79 \mathrm{~min}$, ethanol concentration $72.89 \%(\mathrm{v} / \mathrm{v})$. Under the optimal extraction conditions, the flavonoids yield was about $3.5315 \%$. Statistical analysis of the results showed that extraction temperature, extraction time and ethanol concentration significantly affected the extraction yield of total flavonoids. In addition, the antibacterial activity assays of the flavonoids were carried out and it was demonstrated that the total flavonoids extracted at the optimum conditions had pronounced antibacterial effects against the four bacterial species. Therefore, this study suggested that walnut leaves are promising resources with antibacterial properties for the development of phytomedicines.
\end{abstract}

Keywords: Ultrasound-Assisted Extraction, Response Surface Methodology, Walnut Leaf, Flavonoids

\section{Introduction}

Walnut (Juglans regia L.), which belongs to the Juglandaceae family, is a local deciduous tree in northwestern Chain (2012; Moser, 2012). Walnut leaves are known to possess many biological properties and are easily available in abundant amounts (Derebecka et al., 2012). They have been used as a traditional medicine in China and have shown various health benefits for the treatment of skin inflammations, venous insufficiency and ulcers (Cheniany et al., 2013). Moreover, researches in pharmacology and therapeutics have shown that walnut leaves have hypoglycemic, antioxidative, antimicrobial and antihypertensive effects (Gîrzu et al., 1988). In recent years, there has been an in-depth study on substances having considerable antimicrobial properties. It is well known that certain chemicals produced by plants are naturally toxic to bacteria and fungi. Various medicinal plant extracts containing flavonoids are reported to have antimicrobial activity (Basile et al., 1999).

Walnut leaves are good sources of flavonoids (Zhao et al., 2014). As natural products, flavonoids exert an extensive biochemical and pharmacological properties. They are described as dietary supplements that promote health, prevention of disease and active cancer preventive agents (Duarte et al., 1993; Hodek et al., 2002). Flavonoids are present in photosynthetic cells and are therefore widespread in the plant kingdom (Manthey et al., 2001). They are common ingredient in the human diet and are found in vegetables and fruits (Xie et al., 2007; Harborne and Baxter, 1999). Flavonoids have been shown to possess a series of important biological activities, including antifungal and antibacterial activities (Galeotti et al., 2008; Kabir et al., 2015; Alarcón et al., 2008). Flavonoids compounds can form complexes with soluble proteins and extracellular matrix and bacterial cell walls, which probably lead to their antibacterial 
activities (Cushnie and Lamb, 2005). Presence of flavonoids in plants might have some or significant contribution to the antimicrobial activity of plants.

Up-to now, several traditional extraction methods have been applied to the extraction of flavonoids from walnut leaves such as Maceration Extraction (ME) (Djozan and Assadi, 1995), Heat Reflux Extraction (HRE) (Zhang and Liu, 2004), soxhlet extraction (Shang and Yuan, 2003) and Microwave-Assisted Extraction (MAE) (Xia et al., 2006). This extraction process usually takes several hours or even days and requires a large amount of solvents, which may result in the damage of flavonoids due to hydrolysis and oxidation (Camel, 2000). Ultrasonic Assisted Extraction (UAE) method can extract bioactive molecules at lower temperature, shorter time and also can relatively reduces the structural damage of compounds in plants than using other traditional extraction (Yuan et al., 2015).

Response Surface Methodology (RSM) is a collection of improvement method of optimization mathematical and statistical process (Talebpour et al., 2009). This is a useful tool for studying the mutual effect between various factors on their measurement and quantification of the influence of reaction parameters (Al-Matani et al., 2015; Teng and Choi, 2014). BoxBehnken Design (BBD) is a commonly used process of RSM which make it easier to arrange the experiments result (Borges et al., 2009). Therefore, BBD technology was employed to analyze the influence of various process variables, including extraction temperature, extraction time and ethanol concentration on the yield of the flavonoids extracted from walnut leaves.

In the current study, UAE was used to extract flavonoids from walnut leaves using one factor and RSM experimental design to optimize extraction conditions. Furthermore, the antibacterial effects of the total flavonoids extracted at the optimum conditions were determined by using the diffusion methods of agar well. The purpose of this study was to determine the best extraction process parameters for flavonoids extraction from walnut leaves by ultrasonic assisted method and to explore its potential antibacterial properties, so as to establish a scientific basis for the development and utilization of flavonoids.

\section{Materials and Methods}

\section{Plant Material}

The samples of walnut leaves were harvested between June and July at Zibo city, Shandong province of China and the experimental materials were dried in oven and ground to a powder and then filtered using a 10 mesh sieve.

\section{Chemicals and Reagents}

Rutin (purity $>98 \%$ ), sodium hydroxide, aluminum chloride and aluminum nitrate were obtained from Sigma-Aldrich Chemicals Co, Germany and all are analytical grade.

\section{The Total Flavonoids Extraction from Walnut Leaves}

The powders of walnut leaves $(1 \mathrm{~g})$ were placed in 50 $\mathrm{mL}^{-1}$ centrifuge tubes and mixed with ethanol. After ultrasonic extraction, the samples were centrifuged at $5000 \mathrm{rpm}$ and the supernatant was collected $15 \mathrm{~min}$ later. The residue continued to be extracted twice according to the above mentioned conditions, then all supernatants were mixed up and concentrated by a rotary evaporator, then, flavonoids were separated and purified used large hole resin, finally, the collected fractions were freeze dried to powder.

\section{Determination of the Content of Total Flavonoids}

The total flavonoids content in the extracted solution was measured by an aluminum-chloride-colorimetric method (Qadir et al., 2015). In brief, the Rutin standard and the extracted solution with different concentrations were appropriately diluted by $30 \%$ ethanol to $5 \mathrm{~mL}$ and added $0.3 \mathrm{~mL}$ of $5 \%$ sodium nitrite solution, placed 6 min then added $0.3 \mathrm{ml}$ of $10 \%$ alchlor solution, placed 6 min, then added $4 \mathrm{~mL}$ of $5 \%$ sodium hydroxide solution. Finally, adjusted the volume of the mixture to $10 \mathrm{~mL}$ by $30 \%$ ethanol and placed for $15 \mathrm{~min}$. The absorbance of the mixture was measured at $510 \mathrm{~nm}$ and distilled water was used as a blank control. The reference standard was Rutin, while the contents of total flavonoids in extracts were presented as Rutin equivalents. All determinations were performed in triplicate.

In this work, the total flavonoids of the total extract obtained from the walnut leaves were calculated from the equation of the standard plots (Fig. 1) as follows:

Absorbance $=8.66 \times$ total flavonoids $+0.0004\left(\mathrm{R}^{2}=0.9997\right)$

\section{Single Factor Experiments}

Total flavonoids extraction yield of walnut leaves was influenced by many factors. Therefore, choosing appropriate extraction solvent and extraction method is an important consideration. Based on the preliminary experiments results ethanol and UAE were selected as reasonable options.

The experiment used ethanol as the extraction solvent and UAE as extraction method, respectively. The maximum total flavonoids content were determined by single factor experiments. Before RSM analysis, an initial experiment was performed to screen for important factors affecting the experimental responses. 


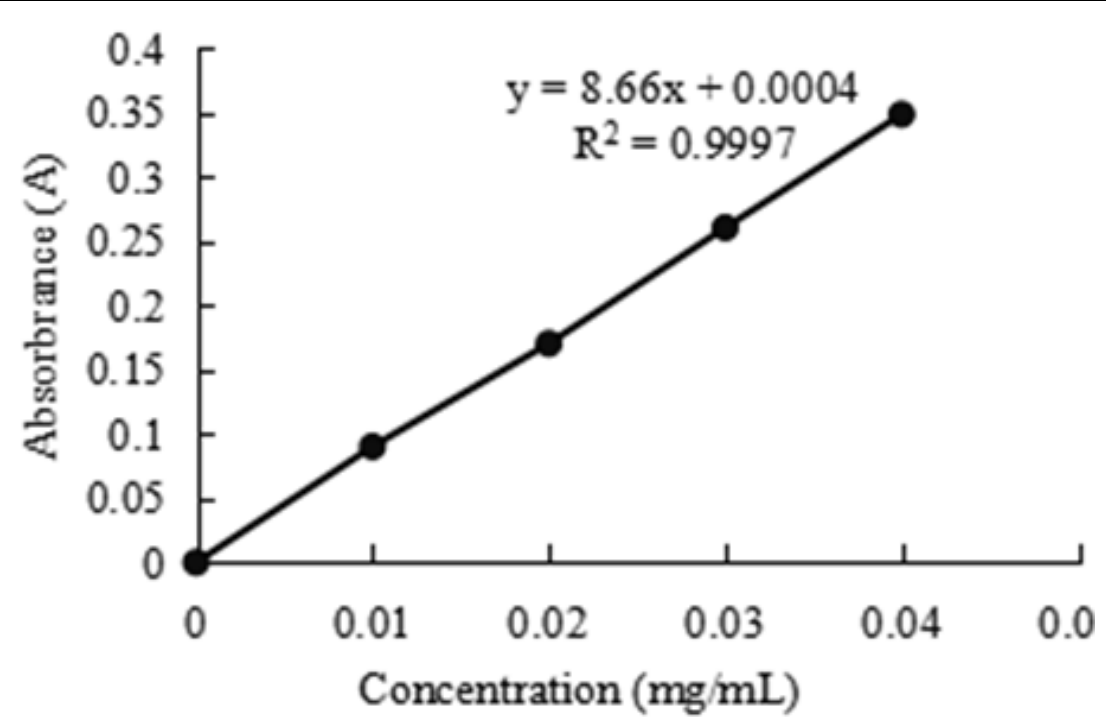

Fig. 1. Calibration curve of standard Rutin for determination of total flavonoids content in total extract of walnut leaves

Ethanol concentration of $30,40,50,60,70$ and $80 \%$, extraction time of $10,20,30,40,50$ and $60 \mathrm{~min}$, extraction temperature of $30,40,50,60,70$ and $80^{\circ} \mathrm{C}$ were investigated using single factor tests to select the impact areas for further investigations.

\section{Box-Behnken Design (BBD) Optimized UAE Conditions}

Box-Behnken Design (BBD) is a frequently used method of RSM that is composed of several intermediate points and a central point (Saniah and Samsiah, 2012). BBD was employed to design the experiments, optimize the extraction conditions and analyze the interactions between the above-mentioned parameters. In the present study, three main factors to RSM were used to describe the relationship between responses and variables to obtain the best extraction conditions. Therefore, the influences of three variables $X_{1}$ (ethanol concentration, 60 to $80 \%$ ), $X_{2}$ (extraction temperature, $30^{\circ} \mathrm{C}$ to $50^{\circ} \mathrm{C}$ ) and $X_{3}$ (extraction time, 20 to $40 \mathrm{~min}$ ) were considered (Table 1). The BBD method was consisted of three factors and levels of 17 experimental operations. In the observed response, the experiment was randomized to maximize the effect of unexplained variability. A quadratic equation was used for this model as follows:

$$
Y=\beta_{0}+\sum_{\mathrm{i}=1}^{3} \beta_{\mathrm{i}} X_{\mathrm{i}}+\sum_{\mathrm{i}=1}^{3} \beta_{\mathrm{ii}} X_{\mathrm{i} 2}+\sum_{\mathrm{i} \neq \mathrm{j}=1}^{3} \beta_{\mathrm{ij}} X_{\mathrm{i}} X_{\mathrm{j}}
$$

Where:

$Y=$ The response variable measurement

$\beta_{0} \quad=$ A constant index

$\beta^{i} \quad=$ The ith liner regression coefficient

$\beta_{i i}=$ ith quadratic coefficient,

$\beta_{i j} \quad=$ ijth interaction coefficient
$X_{i}, X_{j}=$ The leves of independent variable and the term $X_{i}, X_{j}$ and $X_{i}^{2}$ represent the interaction and quadratic terms, respectively

\section{Bacterial Strains and Cultures}

Pure bacterial strains used in this study, including Staphylococcus aureus, Escherichia coli, Salmonella typhi and Bacillus subtilis, were obtained from the Department of Microbiology, Agriculture Culture Collection of China. Separate sterile nutrient agar slants were prepared and the bacterial strains were individually inoculated under aseptic conditions and incubated at $37^{\circ} \mathrm{C}$ for $24 \mathrm{~h}$. Colonies were harvested separately under aseptic condition from the slants and individually inoculated into sterile nutrient broths in separate test tubes and kept in refrigerated condition (Channabasava et al., 2014).

Active cultures were achieved by dispensing a tube of cells into $100 \mathrm{~mL}$ of nutrient broth and incubating at $37^{\circ} \mathrm{C}$ for $10 \mathrm{~h}$. The turbidity of the cell suspension was adjusted to the initial concentration $10^{8} \mathrm{CFU} / \mathrm{mL}$ according to the McFarland standard (Lv et al., 2011).

\section{Antimicrobial Assay}

The effective antibacterial capacity of total flavonoids against bacterial strains was determined by diffusion method of agar well and further confirmed by analyzing the Minimal Inhibitory Concentration (MIC) (Vutuc and Holzer, 2014). The walnut leaves extract was diluted with sterile water to $100 \mathrm{mg} / \mathrm{mL}$. Then pour $100 \mu \mathrm{L}$ bacteria suspension (108 CFU mL) on the solid medium, evenly distributed. Oxford cup of $5 \mathrm{~mm}$ diameter were sterilized, then the cups were set on the medium and different concentration of the extraction $(100 \mu \mathrm{L})$ were filled respectively. 
Table 1. Independent variables and their levels for Box Behnken rotatable design

\begin{tabular}{lllll}
\hline & & Levels & & \\
Factor & symbol & -1 & 0 & 1 \\
\hline Extraction temperature $\left({ }^{\circ} \mathrm{C}\right)$ & $X_{1}$ & 30 & 40 & 50 \\
Extraction time $($ min) & $X_{2}$ & 20 & 30 & 40 \\
Ethanol concentration $(\%)$ & $X_{3}$ & 60 & 70 & 80 \\
\hline
\end{tabular}

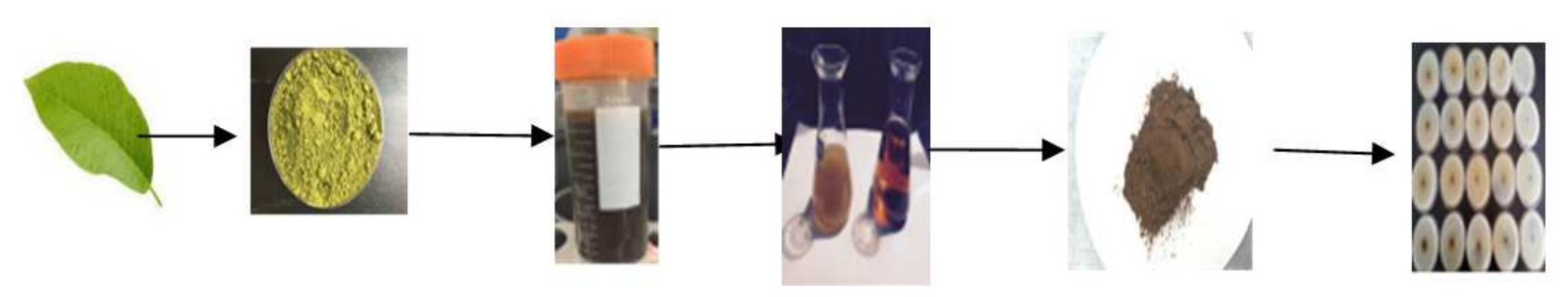

Fig. 2. Schematic representation of total flavonoids extraction from walnut leaves and its antibacterial activity assay

After $48 \mathrm{~h}$ of incubation, the diameter of the inhibitory area was measured with micro scale. The procedure for the extraction of flavonoids and determination of its antibacterial activity was shown in Fig. 2.

\section{Minimum Inhibitory Concentration (MIC) Determination}

Minimum Inhibitory Concentration (MIC) is defined as the lowest concentration of antibacterial agents that inhibits the proliferation of the bacteria (Doss et al., 2011). For the determination of MIC, $100 \mu \mathrm{L}$ bacteria suspension $\left(10^{8} \mathrm{CFU} / \mathrm{mL}\right)$ was added on the medium evenly distributed. Sterilized oxford cup of $5 \mathrm{~mm}$ diameter were prepared, then added with $100 \mu \mathrm{L}$ different concentrations of the extract, which were $100,50,25,12.5,6.25,3.125 \mathrm{mg} / \mathrm{mL}$, respectively and kept at $37^{\circ} \mathrm{C}$ for $24 \mathrm{~h}$. For each microorganism, at least three replicated experiments were carried out for date analysis.

\section{Analysis of Statistical}

Experiments were repeated three times; the mean and standard deviation $(\mathrm{X} \pm \mathrm{SD})$ of the data were calculated. The statistical analyses were carried out using Design-Expert 8.0, spass 20.0 version and Microsoft Excel program (2007).

\section{Results and Discussion}

\section{Single Factor Experiment}

To evaluate the effect of various factors on the extraction of total flavonoids from walnut leaves and to analyze the influences of different variables we designed the single factor experiments (Wang et al., 2012).

\section{Extraction of Total Flavonoids Influenced by Ethanol Concentration}

A fundamental aspect of solvent selection is 'similar dissolution', which indicated that there is a high degree of solubility in the selected solvents (Mustafa and Turner, 2011). A mixture of ethanol and water is usually used to extract flavonoids from different herbs (Garcia-Castello et al., 2015; Luthria et al., 2007). The main reason is that a large amount of phenolic and flavonoids compounds could be dissolved in water and ethanol mixture (Alothman et al., 2009). In addition, the important aspects of solvent selection are economy, security and sustainability. Due to the volatility of ethanol, it is a better fit polar modifier in the choice of extraction solvent. In addition, ethanol has been considered as one of the most safe and environmentally friendly solvents (Otero-Pareja et al., 2015).

To study the influence of ethanol concentration on the total flavonoids extraction from walnut leaves, ethanol concentrations of $30,40,50,60,70$ and $80 \%$ were used. Figure 3 indicated the influence of the ethanol concentration on the extraction yield of flavonoids, the extraction yield of flavonoids was not significantly affected by $30-60 \%$ ethanol; however, peak extraction of total flavonoids was achieved when the alcohol concentration reached $70 \%$, then the extraction yield decreased with ethanol concentration higher than $70 \%$.

Different products are extracted under different conditions. Because of the different chemical structure and polarity of the extracts, solvent has different extraction capacities. Existing studies have shown that the binary solvent system is better than the single-solvent system in extracting flavonoids. It was observed in this study that the optimum yield of flavonoids was obtained at $70 \%$ ethanol, which suggested that the flavonoids in walnut leaves were highly soluble in ethanol-water mixture 
and the yield difference of walnut leaves could be due to different polar and chemical constituents of flavonoids.

\section{Extraction of Total Flavonoids Influenced by Extraction Temperature}

Extraction temperature affects the movement of molecule and heat could promote the dissolution of a large number of compounds (Pompeu et al., 2009). In the present study, the temperatures of $30,40,50,60$, 70 and $80^{\circ} \mathrm{C}$ were selected to study temperature influence on total flavonoids extraction from walnut leaves. Figure 4 presented the influence of the extraction temperature on the extraction yield of flavonoids. When the temperature was increased from
30 to $45^{\circ} \mathrm{C}$, the extraction yield increased and then the extraction yield decreased when the extraction temperature was over $45^{\circ} \mathrm{C}$. The increase in molecular motion is caused by the increase in temperature, so it accelerating the dissolution of flavonoids from plant cells (Lai et al., 2014). As in this study, the appropriate temperature increase in plant cell decomposition and solubility helping to release flavonoids from the substances. But the temperature was too high; it may also cause the damage of the flavonoids. Similar results have also been reported for total flavonoids extraction from alfalfa (Jing et al., 2015). Therefore, $45^{\circ} \mathrm{C}$ is selected as the optimal extraction temperature.

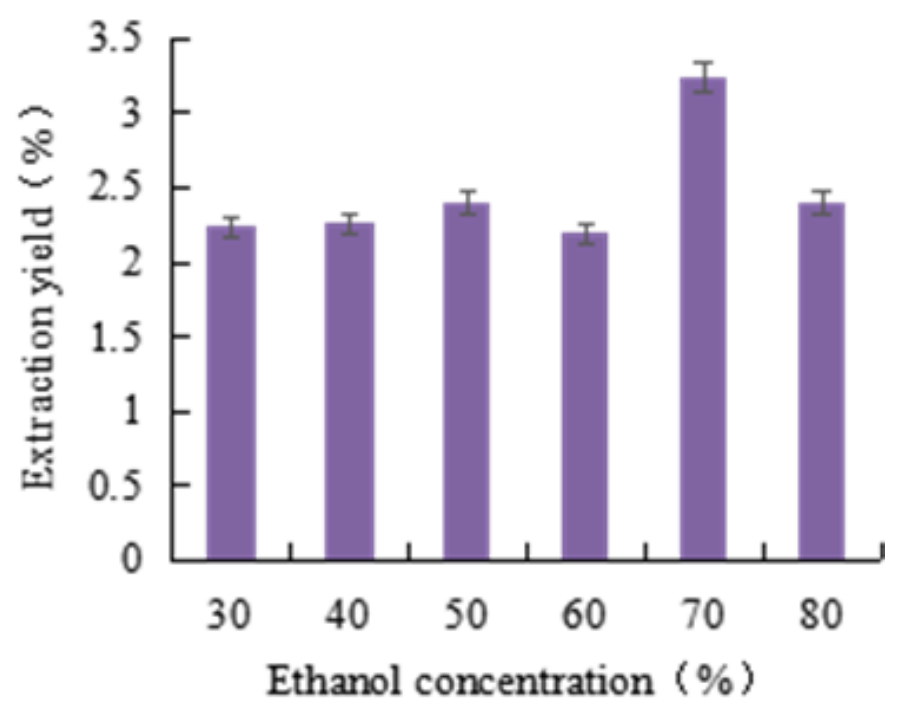

Fig. 3. Effect of the concentration of ethanol on the extraction yield of the walnut leaves

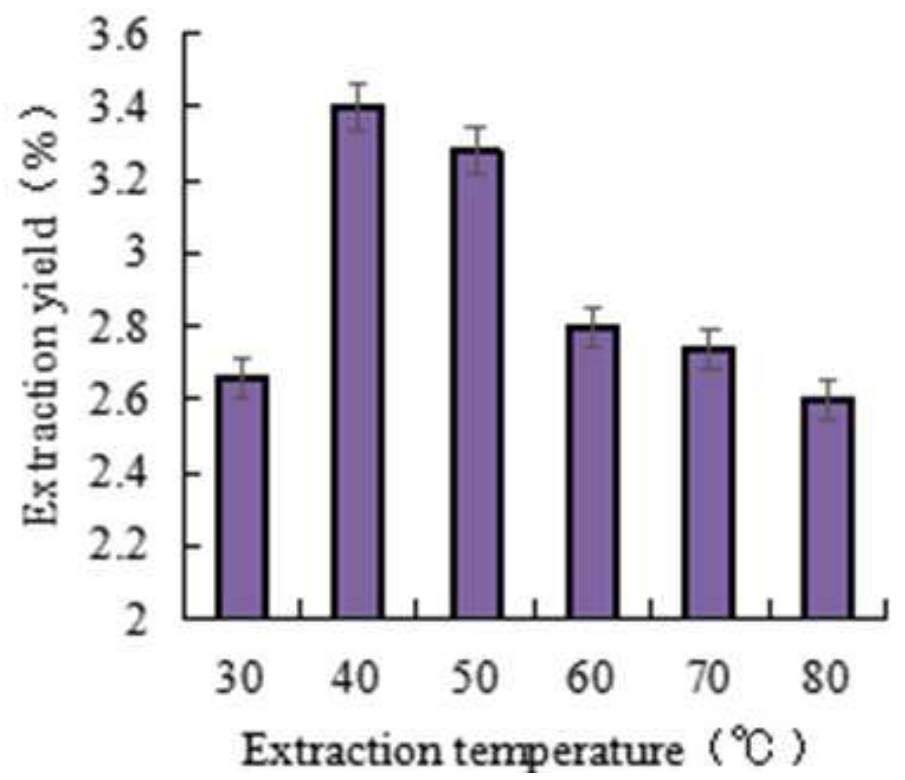

Fig. 4. Effect of the extraction temperature on the extraction yield of the walnut leaves 


\section{Extraction of Total Flavonoids Influenced by Extraction Time}

The time range required of ultrasonic extraction was the third factor investigated, when the other two factors were fixed, e.g., extraction temperature was set at $45^{\circ} \mathrm{C}$ and ethanol concentration was set at $70 \%$, respectively. As indicated in Fig. 5, the extraction time has a significant effect on total flavonoids and the yield increased with the increase of time and then decreased at long extraction time. The maximum yield was achieved at $30 \mathrm{~min}$. The presence of different degrees of flavonoids polymerization and their interaction, may have caused this phenomenon, as the equilibrium between the bulk solution and the solution in the material being reached at different times) (Lissi et al., 1999). Therefore, the optimum extraction time is $30 \mathrm{~min}$.

From the above analysis, we can find that the ethanol concentration, extraction time, extraction temperature are the main factors of the preparation technology and the best extraction conditions were ethanol concentration $70 \%$, extraction time $30 \mathrm{~min}$ and extraction temperature $45^{\circ} \mathrm{C}$.

\section{Data Analysis and Evaluation of RSM Model}

The experiments for RSM model were conducted based on the design matrix under the defined conditions and the responses from the experimental runs were obtained by using 'design expert' (Table 2). A total of 17 runs of experiments were carried out and three individual parameters that affect the flavonoids extraction yield were optimized. Analysis of variance (ANOVE) and the resulting model regression coefficients were presented in Table 3 which demonstrated the contribution of the variable to the quadratic model. A multivariate regression equation was established and the response variable coding level of the independent variable was analyzed. The quadratic polynomial model of walnut leaves flavonoids was predicted by the least square method and the multiple regression coefficients were determined. The responses of flavonoids extraction ratio of walnut leaves were considered in studying the influence of process variable. The extraction yield of total flavonoids and independent variables of walnut leaves were studied and an empirical model was proposed (Equation 1):

$$
\begin{aligned}
& \mathrm{Y} \%=3.7-0.069 \mathrm{X}_{1}+0.059 \mathrm{X}_{2}+0.11 \mathrm{X}_{3}+0.025 \mathrm{X}_{1} \mathrm{X}_{2} \\
& +0.11 \mathrm{X}_{1} \mathrm{X}_{3}-0.10 \mathrm{X}_{2} \mathrm{X}_{3}-0.25 \mathrm{X}_{1}^{2}-0.31 \mathrm{X}_{2}^{2}-0.32 \mathrm{X}_{3}^{2}
\end{aligned}
$$

The variance analysis of the extraction yields of the total flavonoids from the walnut leaves using BoxBehnken design was shown in Table 3. The determination coefficient $\left(\mathrm{R}^{2}\right)$ was 0.9938 , which is greater than 0.8 , indicating a very high correlation (Mirhosseini et al., 2009). The $\mathrm{F}$ value and $\mathrm{P}$ value were 124.75 and 0.9679 , respectively, which indicated the suitability of model that can accurately predict the change of variations. Based on this, the model was used to predict the response. The regression equation coefficients and $p$-values coefficients for total flavonoids extraction were shown in Table 3. The second-order terms of extraction time, extraction temperature and ethanol concentrations $\left(X_{1}^{2}, X_{2}^{2}, X_{3}^{2}\right)$, one interaction parameters $\left(X_{1} X_{3}, X_{2} X_{3}\right)$ and the first-order term of extraction time, extraction temperature and ethanol concentrations $\left(\mathrm{X}_{1}, \mathrm{X}_{2}, \mathrm{X}_{3}\right)$ were extremely significant with a small $P$ value $(p<0.01)$, whereas parameters $\left(\mathrm{X}_{1} \mathrm{X}_{2}\right)$ model term were significant $(\mathrm{p}<0.05)$.

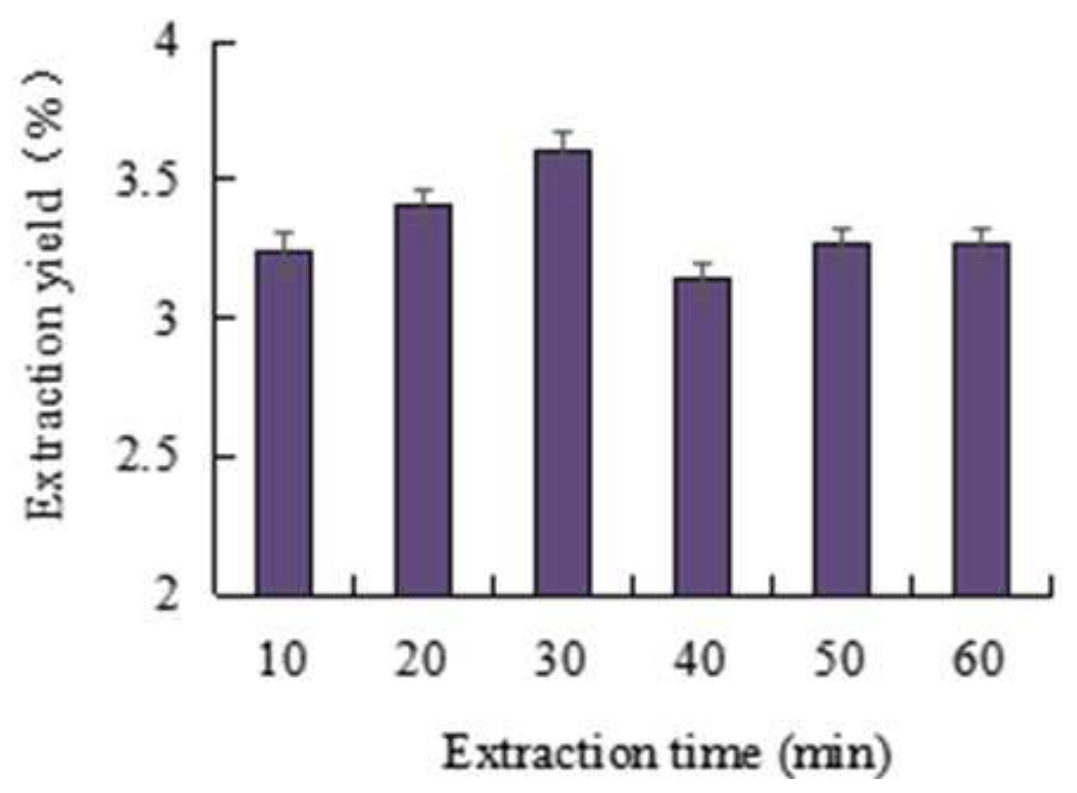

Fig. 5. Effect of the extraction time on the extraction yield of the walnut leaves 
Jingjing Fu et al. / American Journal of Biochemistry and Biotechnology 2017, 13 (4): 176.188 DOI: 10.3844/ajbbsp.2017.176.188

Table 2. Experimental design matrix and result of wanlut leaves extraction yield

\begin{tabular}{lllll}
\hline Run & $X_{1}$ Extraction temperature $\left({ }^{\circ} \mathrm{C}\right)$ & $X_{2}$ Extraction time $(\mathrm{min})$ & $X_{3}$ Ethanol concentrations $(\%)$ & Extract yield $(\%)$ \\
\hline 1 & 40 & 40 & 60 & 3.15 \\
2 & 40 & 20 & 80 & 3.20 \\
3 & 40 & 20 & 60 & 2.80 \\
4 & 40 & 30 & 70 & 3.70 \\
5 & 40 & 30 & 70 & 3.75 \\
6 & 30 & 40 & 70 & 3.24 \\
7 & 40 & 30 & 70 & 3.67 \\
8 & 40 & 40 & 80 & 3.14 \\
9 & 30 & 20 & 70 & 3.20 \\
10 & 40 & 30 & 70 & 3.65 \\
11 & 30 & 30 & 60 & 3.20 \\
12 & 50 & 40 & 70 & 3.14 \\
13 & 50 & 30 & 80 & 3.30 \\
14 & 50 & 20 & 70 & 3.00 \\
15 & 30 & 30 & 80 & 3.20 \\
16 & 50 & 30 & 60 & 2.85 \\
17 & 40 & 30 & 70 & 3.73 \\
\hline
\end{tabular}

Table 3. ANOVA result for the experiment response at different factor level

\begin{tabular}{|c|c|c|c|c|c|c|}
\hline Source & Sum of Squares & $\begin{array}{l}\text { Mean } \\
\text { df }\end{array}$ & $\mathrm{F}$ & $\begin{array}{l}\text { P-value } \\
\text { Square }\end{array}$ & Value & Prob $>$ F \\
\hline Model & 1.46 & 9 & 0.16 & 124.75 & $<0.0001$ & significant \\
\hline $\mathrm{X}_{1}$-Reaction temperature & 0.038 & 1 & 0.038 & 29.17 & 0.0010 & \\
\hline $\mathrm{X}_{2}$-Reaction time & 0.028 & 1 & 0.028 & 21.30 & 0.0024 & \\
\hline $\mathrm{X}_{3}$-Ethanol concentrations & 0.088 & 1 & 0.088 & 68.03 & $<0.0001$ & \\
\hline $\mathrm{X}_{1} \mathrm{X}_{2}$ & $2.500 \mathrm{E}-003$ & 1 & $2.500 \mathrm{E}-003$ & 1.93 & 0.2075 & \\
\hline $\mathrm{X}_{1} \mathrm{X}_{3}$ & 0.051 & 1 & 0.051 & 39.05 & 0.0004 & \\
\hline $\mathrm{X}_{2} \mathrm{X}_{3}$ & 0.042 & 1 & 0.042 & 32.42 & 0.0007 & \\
\hline $\mathrm{X}_{1}^{2}$ & 0.25 & 1 & 0.25 & 194.95 & $<0.0001$ & \\
\hline $\mathrm{X}_{2}^{2}$ & 0.4 & 1 & 0.4 & 312.11 & $<0.0001$ & \\
\hline $\mathrm{X}_{3}^{2}$ & 0.42 & 1 & 0.42 & 327.40 & $<0.0001$ & \\
\hline Residual & $9.075 \mathrm{E}-003$ & 7 & $1.296 \mathrm{E}-003$ & & & \\
\hline Lack of fit & $2.275 \mathrm{E}-003$ & 3 & 7.583E-003 & 0.45 & 0.7334 & not significant \\
\hline Pure Error & $6.800 \mathrm{E}-003$ & 4 & $1.700 \mathrm{E}-003$ & & & \\
\hline Cor Total & 1.46 & 16 & & & & \\
\hline $\mathrm{R}^{2}$ & 0.9938 & & & & & \\
\hline Adj. $R^{2}$ & 0.9858 & & & & & \\
\hline
\end{tabular}

\section{Response Surface Analysis}

The three dimensional response surface plots can make predictive model equations more intuitive. Therefore, the surface response plot of the model is established and the influence of independent variables on the dependent variables is visualized through the adjustment of one factor at the same time (Samimi et al., 2015). In the present experiment, Fig. 6 and 7 showed the three-dimensional (3d) curved surface and twodimensional (2d) contour plot of the experiment.

The influence of extraction temperature and extraction time on the total flavonoids extract yield was analyzed (Fig. 6a and 7a). At a definite extraction time, increasing extraction temperature resulted an increase in extraction yield. However, when extraction temperature was higher than $45^{\circ} \mathrm{C}$ the extraction yield was slightly decreased. It was similar for the extraction time. Therefore we can predict that the optimum extraction time is about $30 \mathrm{~min}$ and optimum extraction temperature is about $45^{\circ} \mathrm{C}$. In addition, the effects of the extraction time and temperature on flavonoids extraction from walnut leaves were very significant.

Figure $6 \mathrm{~b}$ and $7 \mathrm{~b}$ showed the $3 \mathrm{D}$ plot for the extraction yield of flavonoids from walnut leaves with respect to ethanol concentration and reaction temperature. With an increasing extraction temperature the extract yield slightly increased but as the temperature was exceeded $45^{\circ} \mathrm{C}$ the extract yield decreased extremely. When the extraction temperature was constant, the extraction yield increased with the ethanol concentration, then decreased slightly when the ethanol concentration is too high. The optimum ethanol concentration is about $70 \%$.

The influences of extraction time and ethanol concentration on the extraction yield of flavonoids were shown in the Fig. $6 \mathrm{c}$ and $7 \mathrm{c}$. The extraction yield increased with the increase in ethanol concentration, 
however when ethanol concentration was higher than $70 \%$, the extraction yield of flavonoids tend to be stable and slightly decreased. When the concentration of ethanol was constant, the extraction yield of total flavonoids increased with extraction time, as extraction time reached $30 \mathrm{~min}$ the best extraction yield was attainted. While extract yield slightly decreased with the extraction time exceeded $30 \mathrm{~min}$. We can conclude that the optimum extraction time is about $30 \mathrm{~min}$ and the optimum ethanol concentration is about $70 \%$.

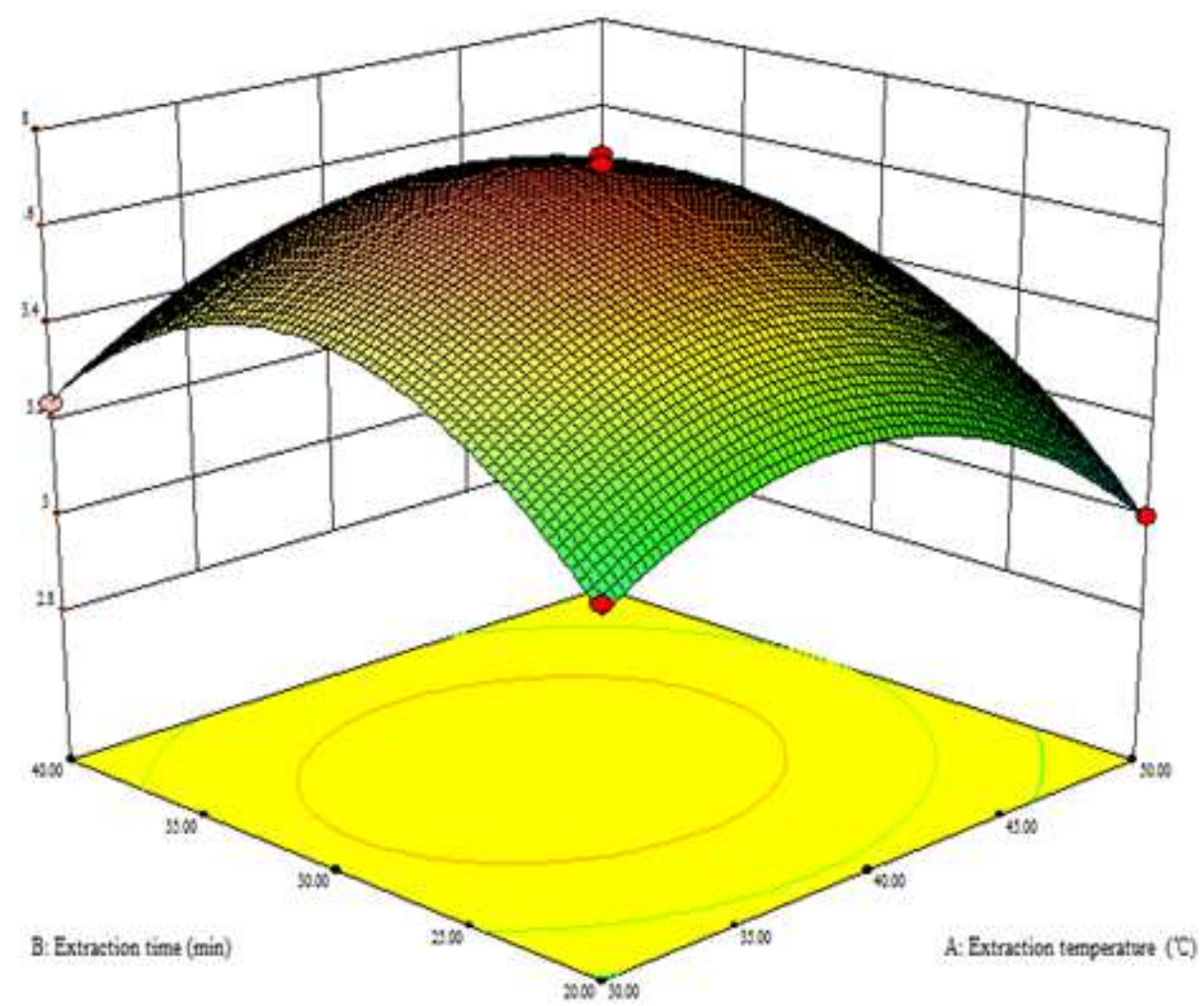

(a)

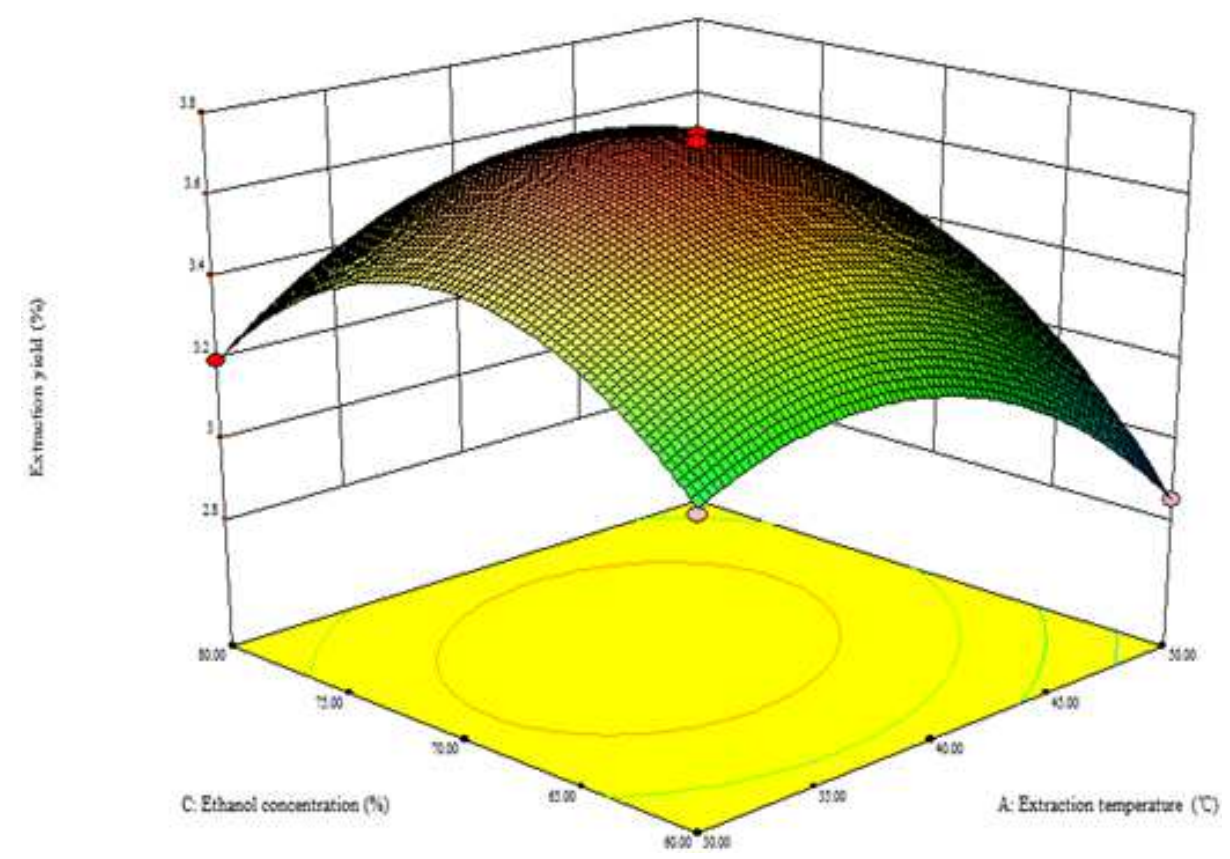

(b) 


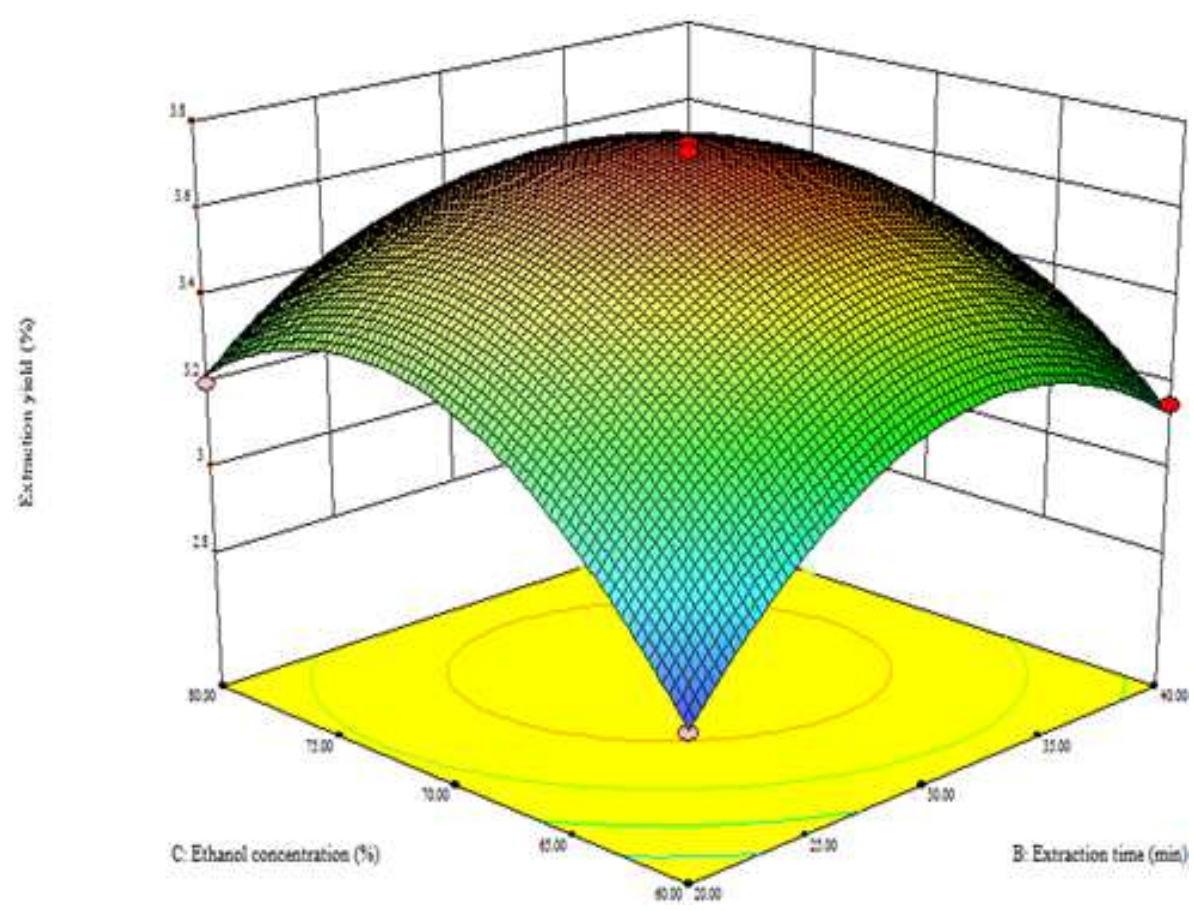

(c)

Fig. 6. 3D surface plots of the average particle size of materials at different experimental factors (a) Extraction temperature versus Extraction time (b) Extraction temperature versus ethanol concentration (c) Extraction time versus ethanol concentration

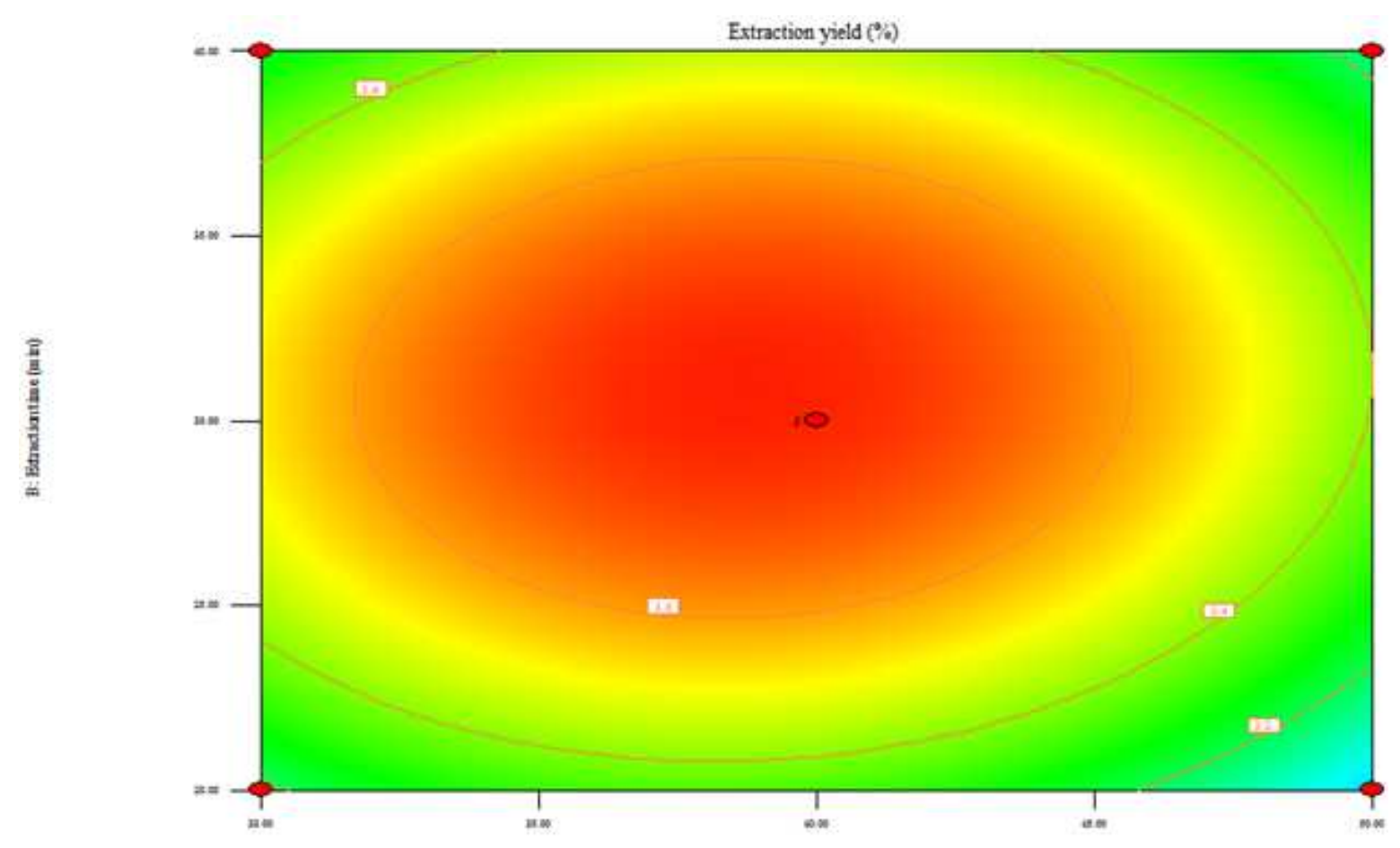

A. Extration tespenatus ( $\mathrm{C}$ )

(a) 


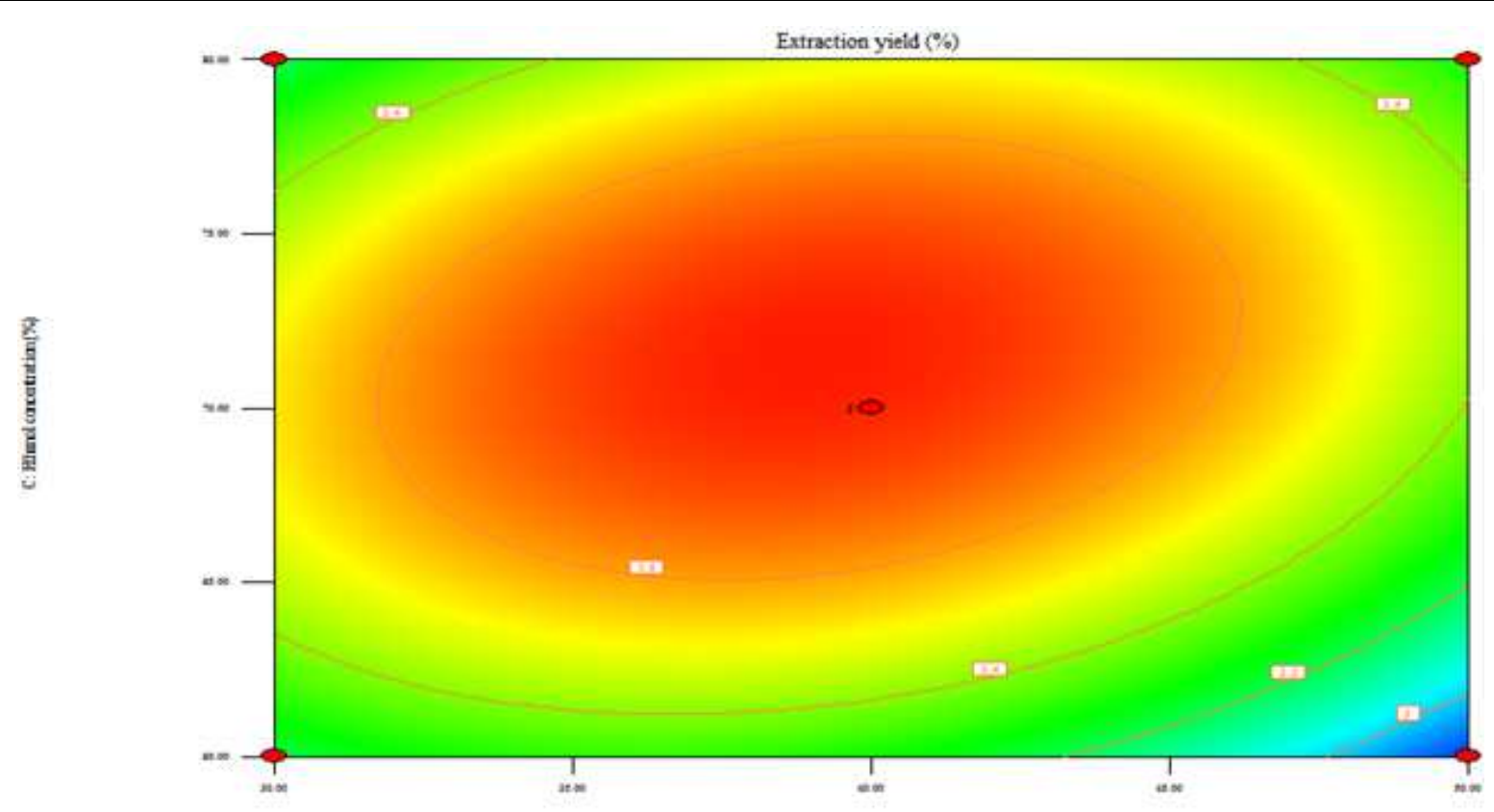

A. Eimation tepentitue ( $(E)$

(b)

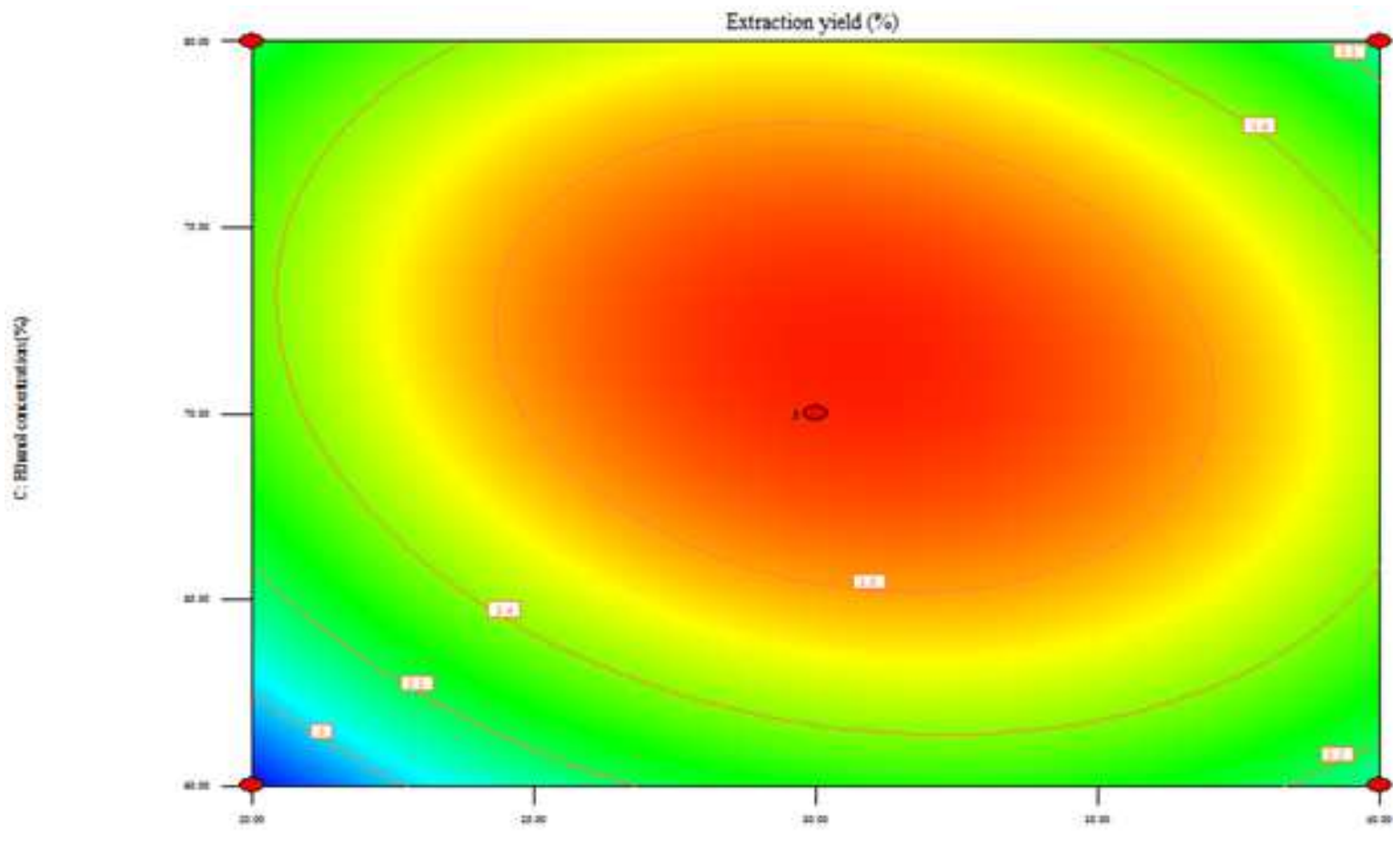

B: Durncticen tist isin?

(c)

Fig. 7. 2D contour plots of the average particle size of materials at different experimental factors (a) Extraction temperature versus Extraction time (b) Extraction temperature versus ethanol concentration (c) Extraction time versus ethanol concentration 
Table 4. Antibacterial activities of the flavonoids extracts from walnut Leaves

Zone of inhibition (mm)

\begin{tabular}{lllll}
\hline Extraction concentration $(\mathrm{mg} / \mathrm{ml})$ & Salmonella typhi & Escherichia col & Bacillus subtilis & Staphylococcus aureus \\
\hline 0 & - & - & - & - \\
100 & $11.3 \pm 0.2$ & $20.69 \pm 0.1$ & $14.73 \pm 0.2$ & $22.32 \pm 0.3$ \\
\hline
\end{tabular}

Table 5. Minimum Inhibitory Concentration of the flavonoids extracts from walnut leaves

\begin{tabular}{lllll}
\hline Zone of inhibition $(\mathrm{mm})$ & & & & \\
Extraction concentration $(\mathrm{mg} / \mathrm{ml})$ & Salmonella typhi & Escherichia coli & Bacillus subtilis & Staphylococcus aureus \\
0 & - & - & - & - \\
\hline 3.125 & - & - & - & - \\
6.25 & - & $10.35 \pm 0.1$ & - & $11.32 \pm 0.2$ \\
12.5 & - & $13.23 \pm 0.3$ & $9.76 \pm 0.35$ & $15.3 \pm 0.2$ \\
25 & - & $15.57 \pm 0.2$ & $11.57 \pm 0.3$ & $17.98 \pm 0.1$ \\
50 & $8.75 \pm 0.4$ & $20.69 \pm 0.3$ & $14.73 \pm 0.2$ & $22.32 \pm 0.35$ \\
100 & $11.3 \pm 0.2$ & & & \\
\hline
\end{tabular}

\section{The Antibacterial Activity Analysis}

Antimicrobial activities of the flavonoids extracts from walnut leaves were tested against selected microorganisms (Table 4). The results indicated that the flavonoids obtained from walnut leaves have antibacterial activity at $100 \mathrm{mg} / \mathrm{mL}^{-1}$ and the bacterial inhibition ring of flavonoids was measured. It indicated that the flavonoids have best antimicrobial activity against Staphylococcus aureusm, followed by Escherichia coli and then Salmonella typhi.

MIC of the extracts recorded was in the range of $12.5-50 \mathrm{mg} / \mathrm{mL}$ (Table 5). In this investigation the MIC value of $12.5 \mathrm{mg} / \mathrm{mL}$ was recorded for Escherichia coli and Staphylococcus aureus. Whereas, MIC for Bacillus subtilis was $25 \mathrm{mg} / \mathrm{mL}$ and for Salmonella typhi was $50 \mathrm{mg} / \mathrm{mL}$, indicating that the walnut leave extracts have significant antimicrobial potential. Because the MIC of the extracts were very small, indicating they were highly efficient. An overview of the biological activity data obtained from the current survey can emphasize that the tested extracts have great potential for inhibiting bacteria. Staphylococcus aureus is of considerable importance because it is considered to be one of the main pathogens of many hospitals and community infections.

\section{Conclusion}

Through this study, RSM was applied in optimizing the total flavonoids compounds extraction from walnut leaves and it was also showed that the UAE is a valid method for obtaining flavonoids from walnut leaves. The maximum extraction yield of $3.53 \%$ was achieved at temperature of $47.73^{\circ} \mathrm{C}$, ethanol concentration of $72.89 \%$ and extraction time of $30.79 \mathrm{~min}$. Then, the extracts of flavonoids were used to determine their antibacterial activity. The results showed that the flavonoids extracted from walnut leaves have comparatively significant antibacterial activities with good MIC values. Our results showed that walnut leaves can be a potential source of important bioactive compounds and play an important role in controlling the growth of disease-causing bacteria but further phytochemical analysis is needed to identify the extract types of compounds that presented in walnut leaves.

\section{Acknowledgment}

This work was supported by the National Natural Science Foundation of China (Grant No 31670064), TaiShan Industrial Experts Programme (tscy 20160101) and starting grant from Shandong University of Technology.

\section{Author's Contribution}

Jingjing Fu: Performed the bench work and drafted the manuscript.

Yuanda Song: Supervised the work, reviewed and revised the manuscript.

Haifang Xiao: Participated in data analysis.

Shaoxuan Yu: Reviewed the manuscript.

Han Wu: Involved in antibacterial assay.

\section{Conflicts of Interest}

The authors declare no conflict of interest.

\section{References}

Alarcón, R., R.C. Flores, S. Ocampos, A. Lucatti and L.F. Galleguillo et al., 2008. Flavonoids from pterocaulon alopecuroides with antibacterial activity. Planta Medica, 74: 1463-1467.

DOI: $10.1055 / \mathrm{s}-2008-1081331$ 
Al-Matani, S.K., R.N.S. Al-Wahaibi and M.A, Hossain, 2015. Total flavonoids content and antimicrobial activity of crude extract from leaves of ficus sycomorus, native to sultanate of Oman. Karbala Int. J. Modern Sci., 1: 166-171. DOI: $10.1016 /$ j.kijoms.2015.11.007

Alothman, M., B. Rajeev and A.A. Karim, 2009. Antioxidant capacity and phenolic content of selected tropical fruits from Malaysia, extracted with different solvents. Food Chem., 115: 785-788. DOI: 10.1016/j.foodchem.2008.12.005

Basile, A., S. Giordano, J.A. Lópezsáez and R.C. Cobianchi, 1999. Antibacterial activity of pure flavonoids isolated from mosses. Phytochemistry, 52: 1479-1482. DOI: 10.1016/S0031-9422(99)00286-1

Borges, K.B., M.T. Pupo, L.A. de Freitas and P.S. Bonato, 2009. Box-behnken design for the optimization of an enantioselective method for the simultaneous analysis of propranolol and 4hydroxypropranolol by CE. Electrophoresis, 30: 2874-2881. DOI: 10.1002/elps.200800821

Camel, V., 2000. Microwave-assisted solvent extraction of environmental samples. Trends Anal. Chem., 19: 229-248. DOI: 10.1016/S0165-9936(99)00185-5

Chain, E.P.O.C.I., 2012. Scientific opinion on the evaluation of the substances currently on the list in the annex to commission directive $96 / 3 / \mathrm{EC}$ as acceptable previous cargoes for edible fats and oils part ii of iii. EFSA J., 10: 1-151.

DOI: $10.2903 /$ j.efsa.2012.2703

Channabasava, M.G., T.S. Sadananda and C.P. Chandrappa, 2014. Phytochemical analysis of loranthus micranthus extracts and their in vitro antioxidant and antibacterial activities. J. Biol. Active Products Nature, 4: 303-315. DOI: $10.1080 / 22311866.2014 .936901$

Cheniany, M., H. Ebrahimzadeh, K. Vahdati, J.E. Preece and A. Masoudinejad et al., 2013. Content of different groups of phenolic compounds in microshoots of Juglans regia, cultivars and studies on antioxidant activity. Acta Physiologiae Plantarum, 35: 443-450. DOI: $10.1007 / \mathrm{s} 11738-012-1087-7$

Cushnie, T.P. and A.J. Lamb, 2005. Antimicrobial activity of flavonoids. Int. J. Antimicrobial Agents, 26: 343-356. DOI: 10.1016/j.ijantimicag.2005.09.002

Derebecka, N., M. Kania and J. Baraniak, 2012. Liść orzecha włoskiego (Juglandis folium) działanie przeciwdrobnoustrojowe oraz bezpieczeństwo stosowania w chorobach skórnych. Postępy Fitoterapii, 3: 197-202.

Djozan, D. and Y. Assadi, 1995. Determination of anthraquinones in rhubarb roots, dock flowers and Senna leaves by normal-phase high performance liquid chromatography. Talanta, 42: 861-5. DOI: 10.1016/0039-9140(95)01500-B
Doss, A., M. Vijayasanthi and V.P. Venkataswamy, 2011. Antimicrobial effects of the flavonoid fractions of mimosa pudica 1 leaves. J. Pharmacy Res., 4: 1438-1439.

Duarte, J., V.F. Pérez, P. Utrilla, J. Jiménez and J. Tamargo et al., 1993. Vasodilatory effects of flavonoids in rat aortic smooth muscle. structureactivity relationships. General Pharmacology the Vascular System, 24: 857-862.

Galeotti, F., E. Barile, P. Curir, M. Dolci and V. Lanzotti, 2008. Flavonoids from carnation (dianthus caryophyllus) and their antifungal activity. Phytochem. Lett., 1: 44-48. DOI:10.1016/j.phytol.2007.10.001

Garcia-Castello, E.M., A.D. Rodriguez-Lopez, L. Mayor, R. Ballesteros and C. Conidi et al., 2015. Optimization of conventional and ultrasound assisted extraction offlavonoids from grapefruit (Citrus paradisi, L.) solid wastes. LWT-Food Sci. Technol., 64: 1114-1122. DOI: 10.1016/j.lwt.2015.07.024

Gîrzu, M., A. Carnat, A.M. Privat, J. Fialip and A.P. Carnat et al., 1998. Sedative effect of walnut leaf extract and juglone, an isolated constituent. Pharm. Biol., 36: 280-286. DOI: 10.1076/phbi.36.4.280.4580.

Harborne, J.B. and H. Baxter, 1999. The Handbook of Natural Flavonoids: Volume 2 of Handbook of Natural Flavonoids. 2nd Edn., Wiley, Chichester, ISBN-10: 047195893X, pp: 1800.

Hodek, P., P. Trefil and M. Stiborova, 2002. Flavonoids-potent and versatile biologically active compounds interacting with cytochromes P450. Chem. Biol. Interact, 139: 1-21. DOI: $10.1016 / \mathrm{S} 0009-2797(01) 00285-\mathrm{X}$

Jing, C.L., X.F. Dong and J.M. Tong, 2015. Optimization of ultrasonic-assisted extraction of flavonoid compounds and antioxidants from alfalfa using response surface method. Molecules, 20: 15550-15571. DOI: $10.3390 /$ molecules200915550

Kabir, M.S.H., M.A.A. Noman, M.M. Rahman, J. Ara and M.M. Hossain et al., 2015. Antibacterial activity of organic and aqueous extracts of Hopea odorata Roxb. leaves and their total flavonoid content. Br. Microbiol. Res. J., 9: 1-7. DOI: 10.9734/BMRJ/2015/19186

Lai, J., H. Wang, D. Wang, F. Fang and F. Wang et al., 2014. Ultrasonic extraction of antioxidants from chinese sumac (Rhus typhina L.) fruit using response surface methodology and their characterization. Molecules, 19: 9019-9032. DOI: $10.3390 /$ molecules 19079019

Lissi, E.A., B. Modak, R. Torres, J. Escobar and A. Urzua, 1999. Total antioxidant potential of resinous exudates from heliotropium species and a comparison of the ABTS and DPPH methods. Free Radical Res., 30: 471-477. DOI: 10.1080/10715769900300511 
Luthria, D.L., R. Biswas and S. Natarajan, 2007. Comparison of extraction solvents and techniques used for the assay of isoflavones from soybean. Food Chem., 105: 325-333.

DOI: 10.1016/j.foodchem.2006.11.047

Lv, F., H. Liang, Q. Yuan and C. Li, 2011. In vitro antimicrobial effects and mechanism of action of selected plant essential oil combinations against four food-related microorganisms. Food Res. Int., 44: 3057-3064. DOI: 10.1016/j.foodres.2011.07.030

Manthey, J.A., K. Grohmann and N. Guthrie, 2001. Biological properties of citrus flavonoids pertaining to cancer and inflammation. Curr. Med. Chem., 8: 135-153. DOI: 10.2174/0929867013373723

Mirhosseini, H., C.P. Tan, N.S.A. Hamid, S. Yusof and B.H. Chern, 2009. Characterization of the influence of main emulsion components on the physicochemical properties of orange beverage emulsion using response surface methodology. Food Hydrocolloids, 23: 271-280. DOI: 10.1016/j.foodhyd.2008.02.007

Moser, B.R., 2012. Preparation of fatty acid methyl esters from hazelnut, high-oleic peanut and walnut oils and evaluation as biodiesel. Fuel, 92: 231-238. DOI: 10.1016/j.fuel.2011.08.005

Mustafa, A. and C. Turner, 2011. Pressurized liquid extraction as a green approach in food and herbal plants extraction: A review. Anal. Chim. Acta, 703: 8-18. DOI: 10.1016/j.aca.2011.07.018

Otero-Pareja, M.J., L. Casas, M.T. Fernándezponce, C. Mantell and M.D.L.O. Ej, 2015. Green extraction of antioxidants from different varieties of red grape pomace. Molecules, 20: 9686-9702. DOI: $10.3390 /$ molecules20069686

Pompeu, D.R., E.M. Silva and H. Rogez, 2009. Optimisation of the solvent extraction of phenolic antioxidants from fruits of euterpe oleracea using response surface methodology. Bioresource Technol., 100: 6076-6082. DOI: 10.1016/j.biortech.2009.03.083

Qadir, U., V.I. Paul and P. Ganesh, 2015. Preliminary phytochemical screening and in vitro, antibacterial activity of anamirta cocculus, (linn.) seeds. J. King Saud University Sci., 27: 97-104.

DOI: $10.1016 / \mathrm{j} . j \mathrm{jksus} .2014 .04 .004$

Samimi, F., Z.K. Modarresi, O. Dehghani, M.R. Rahimpour and A. Bolhasani, 2015. Application of response surface methodology for optimization of an industrial methylacetylene and propadiene hydrogenation reactor. J. Taiwan Institute Chem. Eng., 46: 51-64. DOI: 10.1016/j.jtice.2014.09.003

Saniah, K. and M.S, Samsiah, 2012. The application of stevia as sugar substitute in carbonated drinks using response surface methodology. J. Tropical Agric. Food Sci., 40: 23-34.
Shang, X. and Z. Yuan, 2003. Determination of active components in rhubarb and study of their hydrophobicity by micellar electrokinetic chromatography. Bioorganic Med. Chem. Lett., 13: 617-622. DOI: 10.1016/S0960-894X(02)01043-0

Talebpour, Z., A. Ghassempour, M. Abbaci and H.Y. Aboul-Enein, 2009. Optimization of microwaveassisted extraction for the determination of glycyrrhizin in menthazin herbal drug by experimental design methodology.

Chromatographia, 70: 191-197. DOI: 10.1365/s10337-009-1146-4

Teng, H. and Y.H. Choi, 2014. Optimization of ultrasonicassisted extraction of bioactive alkaloid compounds from rhizoma coptidis (Coptis chinensis Franch.) using response surface methodology. Food Chem., 1: 299305. DOI: 10.1016/j.foodchem.2013.06.136

Vutuc, C. and R. Holzer, 2014. Evaluation of the in vitro interaction of amoxicillin and cotrimoxazole antibiotics against resistant bacterial strains. J. Applied Pharm. Sci., 4: 94-100.

DOI: $10.7324 / J A P S .2014 .40116$

Wang, C., Z. Li, F. Li, M. Chen and Y. Wang et al., 2012. Optimization of microwave assisted extraction conditions for total flavonoids in toona sinensis leaves using response surface methodology. Int. J. Food Eng., 8: 295-300. DOI: 10.1515/1556-3758.1933

Xia, Z., B. Song, L. Jin, D. Hu and C. Diao et al., 2006. Isolation and inhibitory activity against erk phosphorylation of hydroxyanthraquinones from rhubarb. Bioorganic Med. Chem. Lett., 16: 563-568. DOI: 10.1016/j.bmcl.2005.10.047

Xie, S., L. You and S. Zeng, 2007. Studies on the flavonoid substrates of human Udp-Glucuronosyl Transferase (UGT) 2b7. Pharmazie, 62: 625-629. DOI: 10.1691/ph.2007.8.6779

Yuan, J., J. Huang, G. Wu, J. Tong and G. Xie et al., 2015. Multiple responses optimization of ultrasonicassisted extraction by Response Surface Methodology (RSM) for rapid analysis of bioactive compounds in the flower head of chrysanthemum morifolium, ramat. Indus. Crops Products, 74: 192-199. DOI: 10.1016/j.indcrop.2015.04.057

Zhang, H.X. and M.C. Liu, 2004. Separation procedures for the pharmacologically active components of rhubarb. J. Chromatography B Anal. Technol. Biomed. Life Sci., 812: 175-181.

DOI: $10.1016 /$ j.jchromb.2004.08.010

Zhao, M.H., Z.T. Jiang, T. Liu and R. Li, 2014. Flavonoids in Juglans regia 1. leaves and evaluation of in vitro antioxidant activity via intracellular and chemical methods. Sci. World J., 2014: 1-6.

DOI: $10.1155 / 2014 / 303878$ 